\title{
Juguem amb la taula periòdica
}

\author{
Esther Castelló Rico $\bowtie$, Elena Seba Font \\ Institut La Llauna, Badalona
}

L'aprenentatge de la taula periòdica, els seus elements i els seus símbols també es pot realitzar d'una manera divertida. A continuació es presenta una activitat que es pot proposar als alumnes d'ESO dins de la unitat corresponent a l'estudi de l'àtom i de la taula periòdica.

Paraules clau: símbol, element, metall, no metall, taula periòdica, grup, període, nombre atòmic, configuració electrònica

\section{CONTEXT}

A l'hora d'estudiar la unitat didàctica corresponent a l'àtom i la taula periòdica es va proposar als alumnes de $3 r$ d'ESO la realització d'un treball consistent en el disseny i confecció d'algun joc que permetés treballar els continguts d'aquesta unitat.

Aquest joc havia de permetre reforçar els següents conceptes, treballats prèviament a l'aula: noms i símbols dels elements, els seus estats d'oxidació, la seva configuració electrònica per capes i la seva situació a la taula periòdica.

\section{OBJECTIUS}

- Aprendre els símbols i els noms dels elements

- Conèixer els conceptes de nombre atòmic $i$ nombre màssic

- Conèixer els diferents grups i períodes de la taula periòdica

- Saber distingir entre metall i no-metall

- Saber deduir la configuració electrònica per capes d'un element a partir del seu nombre atòmic i a partir de la seva situació a la taula periòdica

- Fomentar la creativitat de l'alumnat

- Fomentar el treball en grup i la col-laboració entre l'alumnat

\section{FENT L'ACTIVITAT}

Es proposà a l'alumnat que es treballés per parelles, disposant d'una setmana per al disseny $\mathrm{i}$ confecció del joc. Passat aquest temps, l'activitat culminaria amb una exposició a classe on es presentaria el joc i s'explicarien les normes.

Els materials podien ser a gust de cadascú (cartolina, cartró-ploma, fulls de plàstic, pintures, retoladors....).

Cada joc podia ser dissenyat amb diferents graus de dificultat segons el nivell de l'alumnat. Això permetria que l'activitat es pogués proposar a cursos superiors o inferiors.

Una vegada fetes totes les presentacions, es va destinar una sessió de classe per tal que tothom provés els diferents jocs.

\section{JOCS PROPOSATS I REALITZATS PER L'ALUMNAT}

\section{Passaelements}

Aquest joc permet treballar tots els conceptes que es vulguin dins del tema d'estructura atòmica i taula periòdica depenent de les preguntes que es plantegin.

Per realitzar aquest joc els alumnes han confeccionat el següent:

- Una corona circular, en cartró ploma, on es representen encerclades totes les lletres de l'abecedari.

- Rodones verdes i vermelles amb cada lletra per indicar una resposta correcta o incorrecta respectivament. Per enganxar-les a la corona es va utilitzar velcro. 
- Per a cada lletra de l'abecedari van idear una definició corresponent a un element que la contingués.

L'objectiu és encertar el màxim nombre de definicions corresponents a les lletres de la rodona relacionades amb els elements químics.

\section{Normes del joc}

Un alumne aguanta la rodona col-locada de manera que el cap li quedi a dins (fig. 1) i contesta les definicions que un altre llegeix. Si respon correctament s'enganxarà en la lletra corresponent una rodona verda i si no una vermella. Ex: F, primer element del grup 17 (resposta: fluor); conté la $\mathrm{P}$, metall noble germà petit d'un altre (resposta: platí).

Quan s'acaben les lletres es comptabilitza el nombre d'encerts. Guanya el jugador que completi la rodona correctament o el que hagi obtingut més rodones verdes.

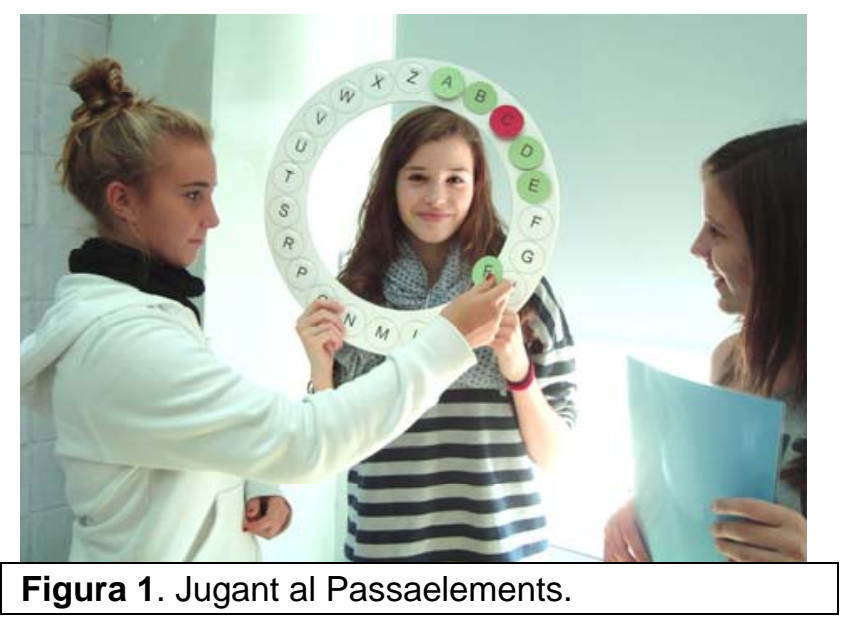

\section{Trencaclosques}

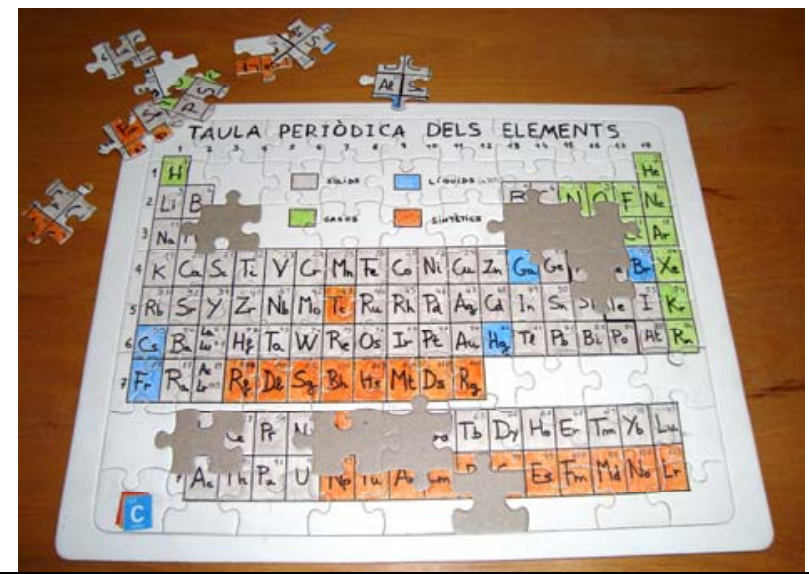

Figura 2. Trencaclosques.
Aquest joc permet treballar els símbols dels elements i la seva situació a la taula periòdica. L'objectiu és confeccionar el trencaclosques.

Per a la realització d'aquest joc els alumnes van utilitzar un trencaclosques en blanc en el que van dibuixar la taula periòdica (fig.2).

\section{Twister}

Amb aquest joc es treballa el nom dels elements i el seu símbol. L'objectiu és reconèixer els símbols dels elements tot encertant-ne les posicions i sense caure a terra (fig. 3).

Per realitzar aquest joc els alumnes van haver de fer servir:

- Cartró ploma per realitzar una ruleta com la representada a la fig. 3 amb una fletxa per assenyalar el símbol i una altra per indicar si han d'utilitzar les mans o els peus

- Una estora de material tou

- Rodones de diferents colors amb els símbols dels elements enganxades a l'estora

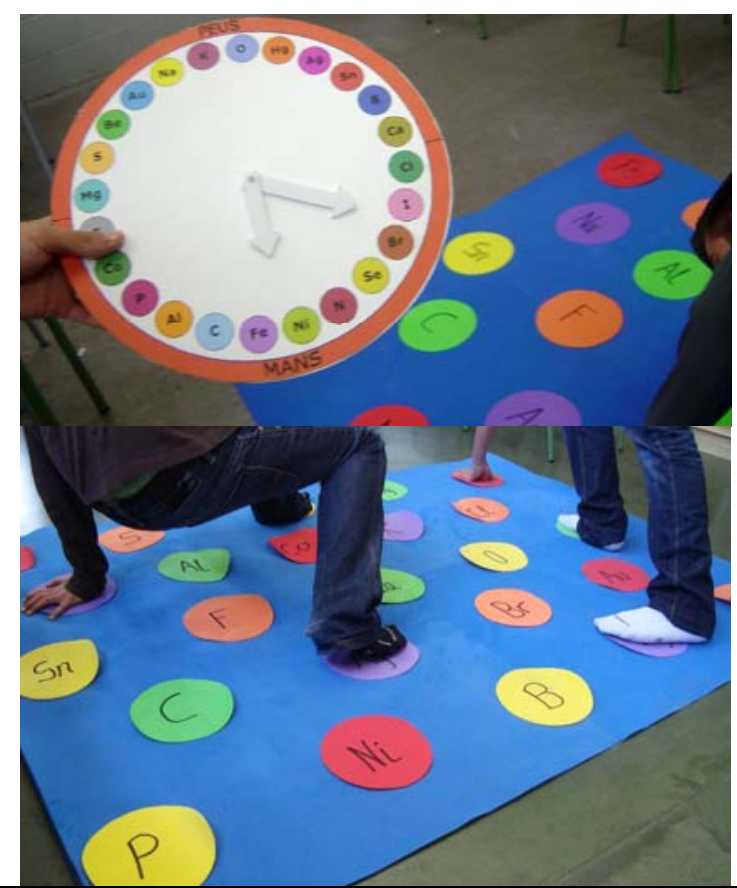

Figura 3. A dalt, ruleta. A sota, jugant al Twister.

\section{Normes del joc}

Un jugador fa girar les dues fletxes de la ruleta. La fletxa petita indica si el que s'ha de moure és una mà o un peu i la gran, el símbol de l'element sobre el qual s'haurà de posar la mà o el peu. El 
jugador que tingui la ruleta haurà de dir el nom de l'element que ha sortit i no el símbol, de manera que també participarà en el joc. L'altre jugador haurà de situar les mans o els peus, segons correspongui, al símbol de l'element que ha sortit.

Per fer-ho més difícil es pot proposar que siguin dos els jugadors que hagin de col-locar mans i peus sobre els cercles. Si un jugador s'equivoca amb el símbol, o bé cau, perd.

\section{TP bingo}

En aquest joc es treballa el nom dels elements, el seu símbol i la seva situació a la taula periòdica (fig. 4).

Es disposarà de:

- Cartolines amb la forma de la taula periòdica amb deu símbols situats al seu Iloc corresponent

- Una bossa amb targetes amb els símbols dels elements

- Fitxes per marcar els elements cantats

\section{Normes del joc}

Un jugador té un bossa amb targetes amb el nom dels elements químics i els va cantant un a un. La resta de jugadors col-loquen una fitxa al símbol de l'element cantat si surt en el cartronet que tenen amb forma de taula periòdica. Quan un jugador ha completat la seva taula canta bingo i guanya.

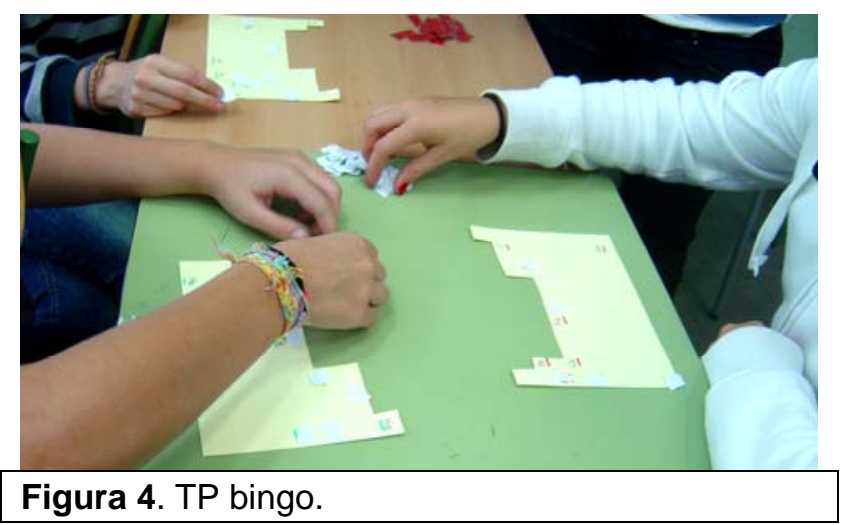

\section{Sopa d'elements}

En aquest joc es treballarà el nom i el símbol dels elements. L'objectiu és ser el primer en trobar tots els noms dels símbols de les fitxes que li han tocat.
Es disposarà de:

- Una cartolina gran amb la sopa de lletres impresa

- Unes targetes amb els símbols dels elements que apareixen a la sopa

\section{Normes del joc}

Cada jugador agafarà cinc targetes amb els símbols dels elements i buscarà els noms corresponents a la sopa de lletres. Guanya el jugador que els localitza primer.

\section{Memory}

En aquest joc es treballa el nom dels elements i el seu símbol. L'objectiu és aparellar el màxim nombre de símbols i noms (fig. 5). Per realitzar el joc els alumnes van confeccionar:

- Unes targes vermelles amb els símbols dels elements

- Unes altres targes grogues amb els noms dels elements corresponents

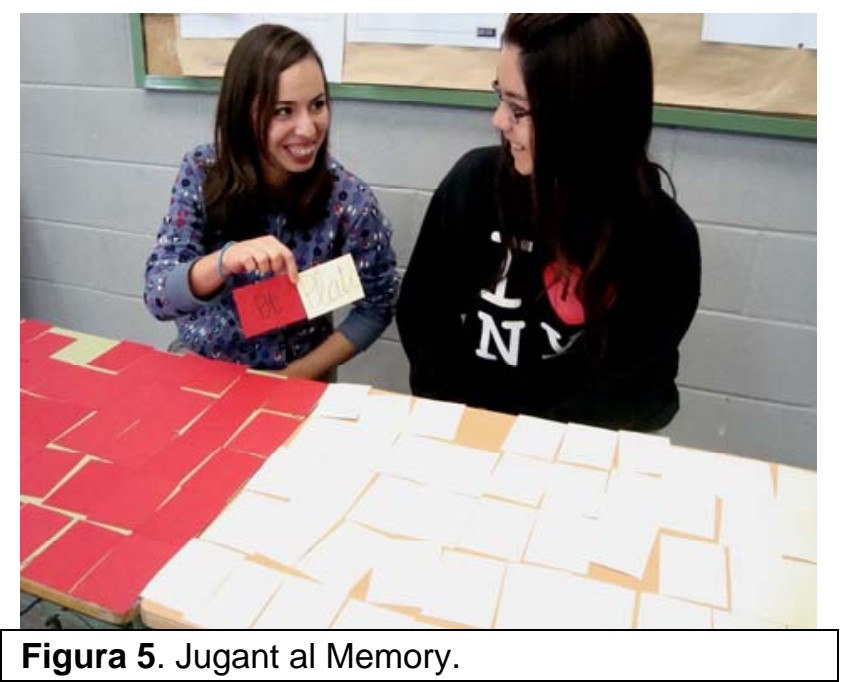

\section{Normes de joc}

Es van dissenyar dues modalitats de joc:

1) Les targes amb el nom dels elements es reparteixen entre els jugadors; les targes que porten els símbols es disposen cap per avall. Cada jugador, quan li arriba el torn, aixeca una de les targes i si coincideix el símbol amb algun nom 
dels que ell té s'elimina la parella. Si no coincideix es torna a col-locar al seu lloc i tant el jugador que té el nom de l'element com els altres han de memoritzar la situació d'aquest símbol, ja sigui per aixecar-lo quan sigui el seu torn si el té com per no aixecar-lo si no el té.

2) Es disposen totes les fitxes amb els símbols cap per avall a una banda i les fitxes amb el noms a l'altra. Cada jugador aixeca una fitxa de cada i si nom i símbol coincideixen, se les queda i continua jugant. Si no coincideixen, es tornen a collocar cap per avall en el seu lloc. Cada jugador han de procurar memoritzar aquesta situació i passa el torn al company següent.

\section{Dòmino}

En aquest joc (fig. 6) es treballa el nom i el símbol dels elements. Per realitzar-lo els alumnes van confeccionar:

- Unes fitxes de cartró ploma on hi figura el símbol d'un element i el nom d'un altre

\section{Normes de joc}

Són les del dòmino però en aquest cas s'han d'aparellar noms i símbols.

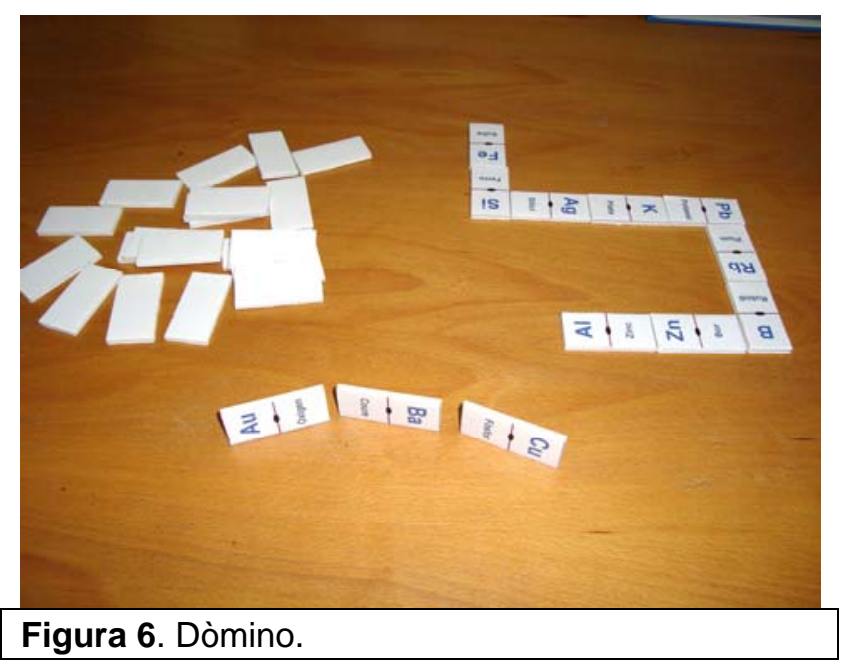

\section{Elements encreuats}

Aquest joc permet treballar tots els conceptes corresponents a aquesta unitat. S'han confeccionat:

- Targetes amb definicions relacionades amb els elements
- Una cartolina on estigui dibuixada l'estructura de l'encreuat

\section{Normes de joc}

Es reparteixen les targetes amb les definicions entre els alumnes i guanya qui les resol en primer Iloc, o bé, es dóna a un grup d'alumnes un full amb totes les definicions horitzontals i verticals i es resolen els encreuats entre tots.

\section{El linx}

Aquest joc permet repassar els símbols i els noms dels elements. L'objectiu és guanyar el nombre màxim de targetes. Es disposa de:

- El taulell de joc (fig. 7) que consisteix en una rodona gran de cartolina on hi ha els símbols del elements encerclats

- Targetes amb els noms dels elements que apareixen a la rodona

\section{Normes de joc}

Cada jugador agafa tres targetes amb noms d'elements i les disposa del revés sobre la taula. Quan tots els jugadors les tinguin, cadascú les gira i les posa sobre el taulell damunt del símbol corresponent a l'element. El jugador que acabi abans guanya les tres targetes i els altres només les que hagin col-locat. Les targetes sense col-locar es tornen. El procés es repeteix fins que s'acaben les targetes.

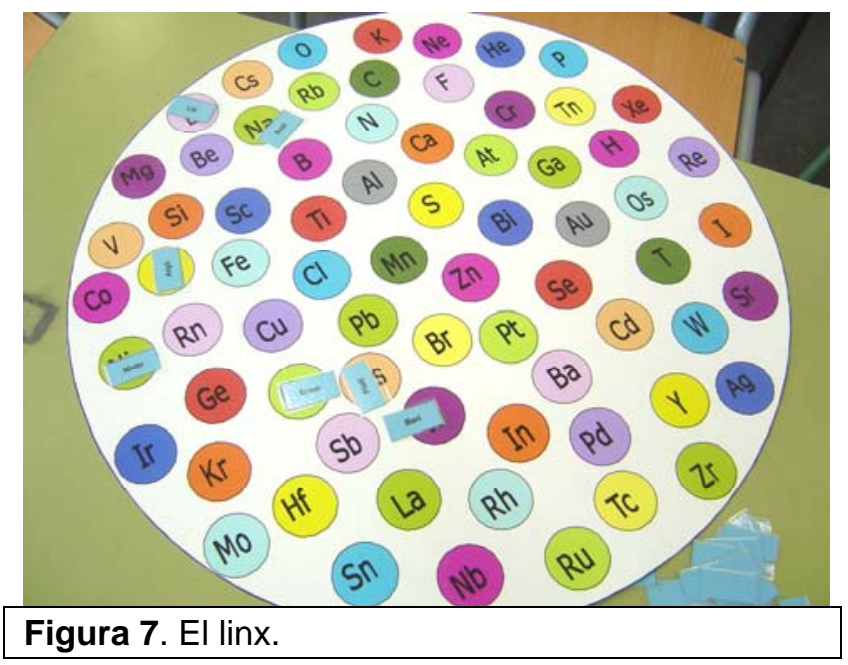

\section{Desenterra elements}

Aquest joc permet treballar el nom i el símbol dels elements i la seva situació a la taula periòdica. 
L'objectiu del joc és endevinar on ha enterrat els elements l'equip contrari. Els alumnes han de disposar de:

- Quatre cartolines amb l'estructura de la taula periòdica

- Gomets vermells i verds

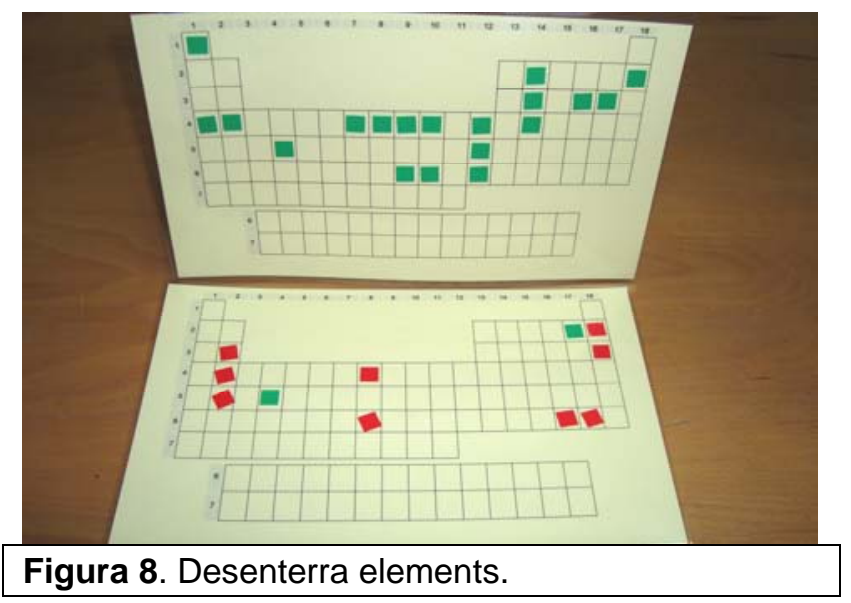

\section{Normes del joc}

Cada equip disposa de dues taules periòdiques (fig. 8) en blanc i gomets vermells i verds. Els gomets verds els disposaran en una de les taules de la manera següent: 3 gomets sols, 3 grups de dos, 2 grups de tres i 1 grup de quatre (en horitzontal o vertical). A l'altra taula hi anirà enganxant gomets verds o vermells segons que endevini o no on estan enterrats els elements de l'equip contrari, tal com es juga en el joc tradicional d'enfonsar vaixells. Per desenterrar un element un jugador ha de dir el nom de l'element corresponent (no la situació).

\section{La gran cursa dels elements}

En aquest joc es treballa el nom i el símbol dels elements, els grups i els períodes de la taula periòdica, les configuracions electròniques per capes dels elements i els seus estats d'oxidació. L'objectiu és aconseguir d'arribar el primer a la casella d'arribada. Es confecciona prèviament:

- $\quad$ un tauler de joc similar al que mostra la figura 9.
- targetes amb el nom dels elements

\section{Normes del joc}

Cada jugador disposa d'una fitxa d'un color i un dau. El primer jugador tira el dau i es situa a la casella corresponent al número que ha sortit, agafa una targeta i contesta la pregunta corresponent al color del número segons la llista següent:

- VERD: símbol

- VERMELL: grup

- TARONJA: període

- BLAU: estats d'oxidació

- LILA: configuració electrònica per capes.

- MARRÓ: el jugador s'atura

- BLAU CLAR: retrocedeix dos llocs i contesta la pregunta corresponent. Si l'endevina pot tornar a tirar i així successivament fins que falli o bé caigui en un número marró.

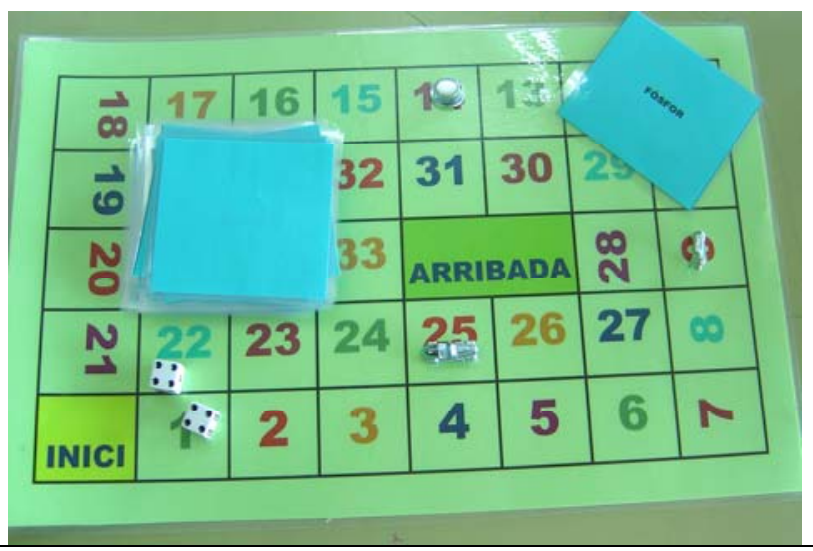

Figura 9. La gran cursa dels elements.

\section{VALORACIÓ DE L'ACTIVITAT}

L'experiència va resultar ser molt positiva. La participació per part dels alumnes va ser molt bona, demostrant la seva creativitat a l'hora d'idear i confeccionar els diferents jocs, tant pel seu contingut com pel seu disseny.

L'expressió oral dels alumnes a l'hora de presentar els jocs que havien dissenyat es va tenir en compte per a l'avaluació final de l'activitat.

En resum es pot dir que va ser una manera lúdica d'aconseguir tots els objectius esmentats que es pretenien assolir. 